UDC 354

Submitted: 05.04.2021

LBC 66.4(2Poc)

Accepted: 10.05.2021

\title{
INTERNATIONAL COOPERATION OF THE RUSSIAN FEDERATION IN HEALTH CARE AMID THE PANDEMIC
}

\author{
Natalia I. Platonova \\ MGIMO University, Moscow, Russian Federation \\ Valeria M. Vargina \\ MGIMO University, Moscow, Russian Federation
}

Introduction: the current epidemiological situation in the world, characterized as a pandemic since March 11, 2020 , has proved the importance of developing national health systems, and also emphasized the need to develop the channels of international cooperation in health care for joint operational measures to combat the spread of the virus. In this regard, the purpose of the study was to determine the prospects for the development of this area and the opportunities for improving the existing systems. Methods: the general scientific methods were used in the research process: logical, system-structural, complex, and functional, as well as the specific scientific methods in the form of the method of concrete-sociological research, the method of modeling, and the formal-legal method. Results: the paper considers the basics of the implementation of international cooperation of the Russian Federation in healthcare amid the pandemic: the differentiation of international cooperation formats is carried out, the legal bases of cooperation are analyzed, and the organization of interaction with the World Health Organization is studied. Justified in the work the trajectories of the development of international cooperation in healthcare are predicted. Conclusions: as a result of the study, it is established that the post-coronavirus era will be characterized by new priorities for cooperation. On the basis of the conducted research, a proposal was made to amend the Federal Law "On the Basics of Public Health Protection in the Russian Federation", as well as the main recommendations for further implementation of international cooperation in healthcare.

Key words: international cooperation of the Russian Federation, public health, health care system, the coronavirus pandemic, the World Health Organization.

Citation. Platonova N.I., Vargina V.M. International Cooperation of the Russian Federation in Health Care amid the Pandemic. Legal Concept = Pravovaya paradigma, 2021, vol. 20, no. 3, pp. 100-107. (in Russian). DOI: https://doi.org/10.15688/lc.jvolsu.2021.3.16

УДК 354

ББК 66.4(2Poc)

Дата поступления статьи: 05.04.2021 Дата принятия статьи: 10.05.2021

\footnotetext{
МЕЖДУНАРОДНОЕ СОТРУДНИЧЕСТВО РОССИЙСКОЙ ФЕДЕРАЦИИ В СФЕРЕ ЗДРАВООХРАНЕНИЯ В УСЛОВИЯХ ПАНДЕМИИ

\section{Наталья Игоревна Платонова}

Московский государственный институт международных отношений (университет) при Министерстве иностранных дел Российской Федерации, г. Москва, Российская Федерация

\section{Валерия Михайловна Варгина}

Московский государственный институт международных отношений (университет) при Министерстве иностранных дел Российской Федерации, г. Москва, Российская Федерация

Введение: современная эпидемиологическая обстановка в мире, характеризуемая с 11 марта 2020 г. как пандемия, доказала важность развития национальных систем здравоохранения, а также подчеркнула необходимость развития каналов международного взаимодействия в сфере здравоохранения в рамках
} 
принятия совместных оперативных мер для борьбы с распространением вируса. В связи с этим целью исследования стало определение перспективы развития данного направления и возможности для совершенствования существующих систем. Методы: в процессе исследования были использованы общенаучные (логический, системно-структурный, комплексный и функциональный) и частнонаучные (метод конкретносоциологических исследований, моделирования, формально-юридический) методы. Результаты: в статье рассмотрены основы реализации международного сотрудничества Российской Федерации в сфере здравоохранения в условиях пандемии: проведена дифференциация форматов международного сотрудничества, проанализированы правовые основы сотрудничества, изучена организация взаимодействия с Всемирной организацией здравоохранения. Спрогнозированы охарактеризованные в работе траектории развития международного сотрудничества в сфере здравоохранения. Выводы: в результате исследования установлено, что для посткоронавирусной эпохи будут характерны новые приоритеты сотрудничества. На основе проведенного исследования высказано предложение внести изменения в Федеральный закон «Об основах охраны здоровья граждан в Российской Федерации», а также представлены основные рекомендации дальнейшей реализации международного сотрудничества в сфере здравоохранения.

Ключевые слова: международное сотрудничество Российской Федерации, здравоохранение, система здравоохранения, пандемия коронавируса, Всемирная организация здравоохранения.

Цитирование. Платонова Н. И., Варгина В. М. Международное сотрудничество Российской Федерации в сфере здравоохранения в условиях пандемии // Legal Concept $=$ Правовая парадигма. -2021 . - T. 20, № 3. C. 100-107.-DOI: https://doi.org/10.15688/lc.jvolsu.2021.3.16

\section{Введение}

11 марта 2020 г. Всемирная организация здравоохранения (далее - ВО3) впервые охарактеризовала сложившуюся ситуацию как пандемию. Современная эпидемиологическая обстановка в мире в очередной раз доказала важность развития национальных систем здравоохранения, а также подчеркнула необходимость развития каналов международного взаимодействия в сфере здравоохранения в рамках принятия совместных оперативных мер для борьбы с распространением вируса.

Анализируя совокупность национальных, региональных и международных норм и принципов, которая лежит в основе реализации международного сотрудничества в сфере здравоохранения, стоит отметить 17 Целей устойчивого развития, среди которых третья «Хорошее здоровье и благополучие» [10], а также Устав профильной международной организации ВО3, где основная цель деятельности в сфере здравоохранения - достижение всеми народами возможного высшего уровня здоровья [3].

Безусловно, здоровье населения также напрямую зависит от степени развитости системы здравоохранения в конкретной стране, так как материальные и нематериальные ресурсы распределены неравномерно. В Указе Президента Российской Федерации от 2020 г. среди национальных целей развития страны до
2030 г. первой упомянута цель сохранения «населения, здоровья и благополучия людей» [15].

\section{Формы международного взаимодействия в сфере здравоохранения в условиях пандемии}

На современном этапе для международного сотрудничества в сфере здравоохранения характерно то, что созданные ранее форматы претерпевают изменения. Вопросы глобального, регионального и национального здравоохранения постепенно проникают в смежные отрасли. Обеспечение здоровья и благополучия человечества, представляя собой основу дальнейшего прогресса и экономического, технологического, научного и политического развития, выходит на повестку дня даже у непрофильных международных организаций. Как следствие, на сегодняшний день международное взаимодействие в области здравоохранения многогранно. Вопросы здравоохранения носят междисциплинарный характер, что приводит к расширению форматов международного сотрудничества в данной области.

В зависимости от количества участвующих сторон, которыми на сегодняшний день могут быть как государственные, так и негосударственные акторы, можно выделить двусторонние и многосторонние формы международного взаимодействия [13, с. 646]. 


\section{ТЕОРИЯ И ПРАКТИКА ГОСУДАРСТВЕННО-ПРАВОВОГО РАЗВИТИЯ}

В более широком смысле формы осуществления международного взаимодействия также зависят от направления реализации совместных действий, они могут быть политическими и профессиональными. Первые предполагают осуществление деятельности по выработке политики в области здравоохранения, вторые взаимодействие специалистов, направленное на реализацию совместных научно-практических проектов и программ [7, с. 101].

Обособленное место в системе международного взаимодействия занимает экспорт медицинских услуг [9]. Данный формат осуществления международной деятельности в сфере охраны здоровья предполагает оказание помощи иностранным гражданам на территории государства. Развитие экспорта медицинских услуг привлекает финансирование в систему здравоохранения, стимулирует ее модернизацию и в настоящее время наращивает потенциал.

Описанная Дж. Наем концепция мягкой силы, направленной на убеждение, а не принуждение реализации интересов конкретных государств, может рассматриваться в контексте осуществления международного сотрудничества в области здравоохранения [17, c. 206]. В связи с этим Россия, будучи донором международной помощи, может использовать институты международного сотрудничества в сфере здравоохранения для продвижения интересов государства и улучшения имиджа страны.

\section{Правовая основа \\ международного сотрудничества в сфере здравоохранения}

Рассматривая правовые основы международного сотрудничества в сфере здравоохранения, стоит отметить, что оно строится на основе системы международного права, обеспечивающего верховенство общих норм и принципов, признаваемых сторонами, вовлеченными в решение общих проблем и задач.

Международно-правовое сотрудничество государств в области здравоохранения характеризуется наличием специфических особенностей: всеохватывающий характер, обособленность юридического инструментария, гибкость правового режима, универсаль- ность, высокая степень взаимозависимости субъектов сотрудничества [1, с. 80].

Существует концепция, согласно которой нормы, затрагивающие процесс оказания медицинской помощи и защиты здоровья населения, являются частью здравоохранительного права [4, с. 15]. Учитывая сложную современную санитарно-эпидемиологическую ситуацию, в настоящее время вопросам здравоохранения уделяется больше внимания, что, вероятно, приведет к модернизации данного правого института в будущем.

Основой международного сотрудничества в сфере здравоохранения являются национальные нормативные правовые акты. В Конституции Российской Федерации закрепляется статус государства как социального, а также право граждан на охрану здоровья и бесплатную медицинскую помощь в государственных и муниципальных учреждениях. Нормы международного права и международные договоры являются составной частью правовой системы страны. В случае их несоответствия нормам российского законодательства, правилам международного договора отдается приоритет. На конституциональном уровне также закрепляется стремление государства к модернизации системы здравоохранения и развития здоровья населения [8].

Основополагающим федеральным законом, регулирующим вопросы оказания медицинской помощи в России, является уже упомянутый ранее Ф3 «Об основах охраны здоровья граждан в Российской Федерации». Данный нормативный правовой акт охватывает вопросы организации системы здравоохранения, процесса оказания медицинской помощи, взаимодействия пациентов и медицинских работников [14]. Однако Ф3 «Об основах охраны здоровья граждан в Российской Федерации» не содержит положений, касающихся международного взаимодействия в области здравоохранения, которое приобретает актуальность в связи с распространением социально значимых инфекционных заболеваний и нестабильной санитарно-эпидемиологической ситуацией.

Полагаем необходимым в ст. 2, раскрывающей основные понятия, используемые в Ф3 «Об основах охраны здоровья граждан в 
Российской Федерации», закрепить определение международного сотрудничества в сфере здравоохранения как деятельности уполномоченных органов государственной власти по взаимодействию с представителями иностранных государств, направленному на совершенствование механизмов охраны здоровья на основе законодательно закрепленных принципов для достижения наиболее высокого уровня здоровья. Данное дополнение обосновано закрепленным в ст. 17 ФЗ «Об основах охраны здоровья граждан в Российской Федерации» полномочием федеральных органов государственной власти в сфере охраны здоровья осуществлять международное сотрудничество в сфере охраны здоровья, в частности заключение международных договоров Российской Федерации [14].

Более того, ст. 9 Ф3 «Об основах охраны здоровья граждан в Российской Федерации» об ответственности органов государственной власти и органов местного самоуправления, должностных лиц организаций за обеспечение прав граждан в сфере охраны здоровья можно дополнить п. 3 , содержащим положение о том, что в процессе обеспечения прав граждан в сфере охраны здоровья органы государственной власти и местного самоуправления должностные лица организаций опираются на лучшую международную практику охраны здоровья. Введение данных изменений будет способствовать повышению значимости международного взаимодействия для достижения наилучшего результата.

\section{Организация сотрудничества}

\section{Российской Федерации}

\section{с Всемирной организацией}

\section{здравоохранения в условиях пандемии}

Основной площадкой для решения глобальных вопросов в сфере здравоохранения остается ВОЗ. Ее рекомендации служат основой для предпринятия мер в связи со сложившейся ситуацией [2]. Россия признает ее как эффективный инструмент реализации политики в сфере глобального здравоохранения.

Российским органом, ответственным за участие страны в деятельности ВОЗ, выступает Министерство здравоохранения РФ в соответствии с Постановлением Правительства
РФ «Об утверждении межведомственного распределения обязанностей по обеспечению участия Российской Федерации в международных организациях системы ООН» [11]. Практическая реализация деятельности происходит в соответствии с двухгодичными соглашениями.

Стоит отметить, что с недавнего времени Российская Федерация закрепила свое положение в качестве государства-донора международной помощи (особенно в условиях борьбы с коронавирусной инфекцией), направляя отечественных специалистов за рубеж, разрабатывая вакцину и участвуя в других процессах, имевших ключевое значение для сохранения здоровья и жизни населения. Доля Российской Федерации в финансировании деятельности ВОЗ составляет 1,78 \% (41,8 млн долл. США). Для сравнения, доля Германии, занимающей лидирующую позицию, составляет 22,39 \% (525,8 млн долл. США) [18].

Представитель ВО3 в Российской Федерации Мелита Вуйнович не раз позитивно оценивала работу российских медиков, а также высокую эффективность и своевременность принимаемых мер в стране [6]. Важную роль в этом сыграли волонтерские организации, активно вовлеченные в процессы оказания помощи населению. Эпидемиологическая ситуация в России связана с высоким уровнем заражения и низкой долей смертности среди инфицированного населения. Данная тенденция, в частности, объясняется демографической спецификой региона и указывает на высокий уровень развития системы здравоохранения.

Взаимодействие ВОЗ и национальных органов можно проиллюстрировать примером совместного заседания внутри фракционной группы Первого заместителя руководителя фракции «Единая Россия» Адальби Шхагошева и представителя ВОЗ Мелитой Вуйнович 30 апреля 2020 года. Круг обсуждаемых вопросов был достаточно широким. В первую очередь было принято решение об участии ВО3 в информировании граждан о коронавирусной инфекции через официальный портал Государственной Думы РФ. Кроме того, обсуждалась эффективность принятых в России мер и дальнейших перспектив развития ситуации, организации тестирования и лечения пациентов с коронавирусом. В России высоко 


\section{ТЕОРИЯ И ПРАКТИКА ГОСУДАРСТВЕННО-ПРАВОВОГО РАЗВИТИЯ}

оценивают роль международного взаимодействия в решении глобальных вопросов, поэтому были затронуты вопросы координации проведения научных исследований, разработки вакцин, протоколов лечения пациентов. Утилизация использованных средств индивидуальной защиты и других отходов, возникающих в процессе оказания медицинской помощи, также обсуждалась участниками встречи. Мелита Вуйнович озвучила выработанные рекомендации для стабилизации обстановки [5].

Разработка российской вакцины от коронавируса оказала влияние на векторы развития международного сотрудничества Российской Федерации в условиях пандемии. Зарегистрировав первую в мире вакцину, разработанную НИЦ им. Гамалеи, Россия внесла весомый вклад в процесс стабилизации обстановки в мире. В ВО3 позитивно оценили участие страны в разрешении кризисной ситуации. Однако на данный момент вопрос о включении российской вакцины от коронавируса в COVAX (инициатива сотрудничества в интересах справедливого доступа к вакцинам против COVID-19) и в перечень лекарственных средств, одобренных ВОЗ для использования в чрезвычайных ситуациях (Российская Федерация уже подала заявку на внесение Спутника-V в данный перечень), находится в процессе рассмотрения [2; 9]. Критерии готовности вакцины были определены ВО3 уже весной 2020 года.

\section{Основные направления международного взаимодействия в условиях пандемии}

На развитие здравоохранения также оказал прямое влияние научно-технический прогресс. Так, актуальной тенденцией развития глобального здравоохранения является внедрение цифровых технологий: интернет-навигация граждан в системе здравоохранения, профилактика заболеваний и контроль за здоровьем, телемедицина, дистанционное образование, поддержка научных исследований, развитие соответствующей инфраструктуры [12, с. 112-115].

Важной тенденцией остается профилактика заболеваний. Именно превентивные меры являются наиболее эффективными, в том числе с экономической точки зрения. Международная политика в сфере здравоохранения направлена на укрепление здоровья людей и пропаганду здорового образа жизни [16].

Кроме того, вопросы охраны здоровья постепенно становятся совокупной частью системы безопасности. Некоторые страны обратились к Совету Безопасности ООН для признания коронавируса угрозой международному миру и безопасности.

Прогнозируя дальнейшее развитие международного взаимодействия в области здравоохранения, можно выделять ряд направлений деятельности, которые приобрели актуальность после стремительного распространения коронавирусной инфекции. Как правило, они уже озвучивались на международных площадках, однако сложившаяся кризисная обстановка стимулировала их пересмотр и доработку. Среди этих направлений можно выделить: корректировку дорожных карт для дальнейшего устойчивого развития; модернизацию механизмов готовности и реагирования на глобальные вызовы и угрозы; пересмотр концепции безопасности; вакцинацию и развитие профилактической медицины; цифровизацию здравоохранения; при условии достаточной кадровой обеспеченности. Они актуальны для развития в краткосрочной перспективе и являются основой для принятия стратегических решений на международном уровне.

Новые тенденции развития международных отношений и изменение основных направлений международной повестки в области здравоохранения откроют перед мировым сообществом не только перспективы для модернизации и улучшения качества жизни, но и повлекут за собой появление новых вызовов и угроз в области глобального здравоохранения. Пандемия коронавируса позволила поновому взглянуть на существующие системы оказания медицинской помощи и развития здравоохранения.

\section{Выводы}

В результате проведенного исследования можно выделить следующие рекомендации для осуществления международного сотруд- 
ничества в сфере здравоохранения Российской Федерации.

Во-первых, пандемия коронавируса может стать отправной точкой для изменения имиджа России на международной арене. Благодаря приобретению статуса донора гуманитарной помощи дальнейшее сотрудничество в сфере здравоохранения будет способствовать укреплению международных связей и авторитета на международной арене.

Во-вторых, учитывая сложившуюся в мире ситуацию и особенности научно-технологического прогресса, представляется необходимым продолжать процесс цифровизации здравоохранения на основе имеющегося опыта. Расширение каналов онлайн-взаимодействия между лечебными учреждениями, научным сообществом, медицинскими работниками и пациентами будет способствовать более оперативному и эффективному принятию решений относительно здоровья населения. В России уже функционирует Единая государственная информационная система в сфере здравоохранения (ЕГИСЗ), в Москве запущена Единая медицинская информационно-аналитическая система (ЕМИАС) и Система социального мониторинга. Многие административные функции (запись к врачу, запись на вакцинацию и другие) также доступны онлайн на портале «Госуслуги» [9].

В-третьих, базой для реализации вышеупомянутых направлений, безусловно, будут служить высоквалифицированные кадры, представляющие государство не только в рамках национальных систем оказания медицинских услуг, но и на международных политических, экономических, научных, технологических и других площадках, посвященных развитию сферы здравоохранения. Отдельно стоит выделить увеличение числа российских специалистов в ВО3.

В рамках практической реализации дальнейшего международного сотрудничества в области здравоохранения рекомендуется внести изменения в действующий ФЗ «Об основах охраны здоровья граждан в Российской Федерации» в части регулирования вопросов международного взаимодействия медицинских учреждений, профессионалов с зарубежными партнерами для реализации совместной деятельности, направленной на развитие здравоохранения. Полагаем необходимым допол- нить ст. 2 и ст. 9 ФЗ «Об основах охраны здоровья граждан в Российской Федерации» необходимыми положениями.

\section{СПИСОК ЛИТЕРАТУРЫ}

1. Воронцов, А. Л. Международно-правовое взаимодействие государств в области охраны здоровья: анализ современной практики / А. Л. Воронцов, Е. В. Воронцова // Lex russica. - 2018. C. 71-82. - DOI: https://doi.org/10.17803/17295920.2018.134.1.071-082.

2. Всемирная организация здравоохранения. Электрон. текстовые дан. - Режим доступа: https:// www.who.int/ru (дата обращения: 12.03.2021). - Загл. с экрана.

3. Всемирная организация здравоохранения. Устав (Конституция) Всемирной организации здравоохранения от 22 июля 1946 // Всемирная организация здравоохранения. - Электрон. текстовые дан. Режим доступа: https://apps.who.int/gb/bd/PDF/bd47/ RU/constitution-ru.pdf?ua=1 (дата обращения: 12.03.2021). -Загл. с экрана.

4. Глашев, А. А. Медицинское право. Практическое руководство для юристов и медиков. - М. : ВолтерсКлувер, 2004. - 202 с.

5. Государственная Дума РФ. - Электрон. текстовые дан. - Режим доступа: http://duma.gov.ru (дата обращения: 12.03.2021). - Загл. с экрана.

6. Карабут, Т. В ВОЗ оценили действия российских медиков в пандемию как образцовые / Т. Карабуг // Российская газета. - 2021. - 2 янв. - Электрон. текстовые дан. - Режим доступа: https://rg.ru/ 2021/01/02/v-voz-ocenili-dejstviia-rossijskih-medikovv-pandemiiu-kak-obrazcovye.html (дата обращения: 12.03.2021). - Загл. с экрана.

7. Карпенко, А. М. Развитие глобального здравоохранения в контексте мировой политики в XXI веке : $23.00 .04:$ дис. ... канд. полит. наук / Карпенко Александр Михайлович. - СПб., 2020. $392 \mathrm{c}$.

8. Конституция Российской Федерации (принята всенародным голосованием 12.12 .1993 с изменениями, одобренными в ходе общероссийского голосования 01.07.2020) // Российская газета. - 2020. 4 июля (№ 144).

9. Министерство здравоохранения. - Электрон. текстовые дан. - Режим доступа: https:// minzdrav.gov.ru/ru (дата обращения: 12.03.2021). Загл. с экрана.

10. Организация Объединенных наций. - Электрон. текстовые дан. - Режим доступа: https:// www.un.org/ru (дата обращения: 12.03.2021). - Загл. с экрана. 
11. Постановление Правительства РФ «Об утверждении межведомственного распределения обязанностей по обеспечению участия Российской Федерации в международных организациях системы ООН» от 3 июня 2003 г. № 323 // Собрание законодательства РФ. - 2003. - № 23. - Ст. 2238.

12. Развитие интернет-технологий в здравоохранении Российской Федерации / Г. Лебедев [и др.] // Public Health Panorama. - 2019. - Vol. 5, iss. 1.C. $112-119$.

13. Современные международные отношения : учебник / под ред. А. В. Торкунова, А. В. Мальгина ; Московский государственный институт международных отношений (Университет) МИД России. - М. : Аспект Пресс, 2017. -688 с.

14. Федеральный закон «Об основах охраны здоровья граждан в Российской Федерации» от 21 ноября 2011 № 323-Ф3 // Собрание законодательства РФ. - 2011. - № 48. - Ст. 6724.

15. Указ Президента РФ «О национальных целях развития Российской Федерации на период до 2030 года» от 21 июля 2020 г. № 474 // Собрание законодательства РФ. - 2020. - № 30. - Ст. 4884.

16. Deloitte. Прогноз развития мировой отрасли здравоохранения // Deloitte. - Электрон. текстовые дан. - Режим доступа: https://www2.deloitte.com /ru/ru/pages/life-sciences-and-healthcare/articles/ global-health-care-sector-outlook.html (дата обращения: 12.03.2021). - Загл. с экрана.

17. Nye, J. S. Jr. Soft Power. The Means to Success in World Politics / J.S.Jr. Nye. - N. Y. : Public Affairs, 2004. $-206 \mathrm{p}$.

18. World Health Organization. Financial Flow // World Health Organization. - Electronic text data. - Mode of access: http://open.who.int/202021/budget-and-financing/flow (date of access: 12.03.2021). - Title from screen.

\section{REFERENCES}

1. Vorontsov A.L., Vorontsova E.V. Mezhdunarodno-pravovoe vzaimodejstvie gosudarstv v oblasti ohrany zdorov'ja: analiz sovremennoj praktiki [International Cooperation of States in the Field of Health Protection: Analysis of Current Practices]. Lex russica, 2018, pp. 71-82. URL: https://doi.org/10.17803/ 1729-5920.2018.134.1.071-082 (accessed 12 March 2021).

2. Vsemirnaja organizacija zdravoohranenija [World Health Organisation], 2021. URL: https:// www.who.int/ru (accessed 12 March 2021).

3. Vsemirnaja organizacija zdravoohranenija. Ustav (Konstitucija) Vsemirnoj organizacii zdravoohranenija ot 22 ijulja 1946 [Constitution of World Health Organisation], 2021. URL: https://
apps.who.int/gb/bd/PDF/bd47/RU/constitutionru.pdf?ua $=1$ (accessed 12 March 2021).

4. Glashev A.A. Medicinskoe pravo. Practicheskoe rukovodstvo dlya yuristov y medikov [Medical law. Handbook for Lawyers and Doctors]. Moscow, Walters Kluver Publ., 2004. 202 p.

5. Gosudarstvennaja Duma [State Duma], 2021. URL: http://duma.gov.ru (accessed 12 March 2021).

6. Karabut T. VOZ ocenili dejstvija rossijskih medikov v pandemiju kak obrazcovye [WHO Evaluated Actions of Russian Doctors During Pandemic As Exemplary]. Rossiyskaya gazeta, 2021. URL: https://rg.ru/2021/01/02/v-voz-ocenili-dejstviiarossijskih-medikov-v-pandemiiu-kak-obrazcovye.html (accessed 12 March 2021).

7. Karpenko A.M. Razvitie globalnogo zdravoohranenia $v$ kontekste mirovoy politiki $v$ XXI veke: dis. ... kand. polit. nauk.: 23.00.04 [Development of Global Healthcare in the Context of World Politics in $21^{\text {st }}$ Century. Dr. polit. sci. diss.: 23.00.04]. Saint Petersburg, 2020.392 p.

8. Konstitucija Rossijskoj Federacii (prinjata vsenarodnym golosovaniem 12.12.1993 sizmenenijami, odobrennymi v hode obshherossijskogo golosovanija 01.07.2020) [Constitution of the Russian Federation]. Rossiyskaya gazeta, 2009, 21 Jan. (iss. 7).

9. Ministerstvo zdravoohranenija [Ministry of Health], 2021. URL: https://minzdrav.gov.ru/ru (accessed 12 March 2021).

10. Organizacija Ob'jedinennyh nacij [United Nations], 2021. URL: https://www.un.org/ru/ (accessed 12 March 2021).

11. Postanovlenie Pravitelstva RF “Ob utverzhdenii mezhvedomstvennogo raspredeleniya obyazannostey po obespecheniyu uchastiya Rossiyskoy Federacii v mezhdunarodnyh organizaciyah sistemy OON" [Decree of the Government of the Russian Federation "On Approval of the Interdepartmental Distribution of Responsibilities for Ensuring the Participation of the Russian Federation in International Organizations of the UN System"]. Sobranie zakonodatelstva RF, 2003, no. 23, art. 2238.

12. Lebedev G., et al. Razvitie internet-tehnologiy $\mathrm{v}$ zdravoohranenii [Development of InternetTechnologies in the Healthcare]. Public Health Panorama, 2019, vol. 5, iss. 1, pp. 112-119. URL: https:/ /apps.who.int/iris/bitstream/handle/10665/325142/ php-5-1-112-121-rus.pdf?sequence $=1$ \&isAllowed $=y$ (accessed 12 March 2021).

13. Torkunov A.V., Malgin A.V. Sovremenniye mezhdunarodnye otnoshenia: uchebnik [Modern International Relations: A Student Book]. Moscow, Aspekt Press Publ., 2017. 688 p.

14. Federalniy zakon "Ob osnovah ohrany zdoroviya graxhdan v Rossiyskoy Federacii” [Federal 
Law "On the Basics of Health Care of Citizens in Russian Federation]. Sobranie zakonodatelstva RF, 2011, no. 48, art. 6724 .

15. Ukaz Prezidenta RF “O nacionalnyh celyah razvitiya Rossiyskoy Federacii na period do 2030 goda" [The Orden of the President "On the National Goals of the Russian Federation for the Period Till 2030 year]. Sobranie zakonodatelstva RF, 2020, no. 30, art. 4884 .
16. Deloitte, 2021. URL: https:// www2.deloitte.com/ru/ru/pages/life-sciences-andhealthcare/articles/global-health-care-sectoroutlook.html (accessed 12 March 2021).

17. Nye J.S.Jr. Soft Power. The Means to Success in World Politics. New York, Public Affairs, 2004. 206 p.

18. World Health Organization. Financial Flow, 2021. URL: http://open.who.int/2020-21/budget-andfinancing/flow (accessed 12 March 2021).

\section{Information About the Authors}

Natalia I. Platonova, Candidate of Sciences (Jurisprudence), Associate Professor, Department of Legal Fundamentals of Management, MGIMO University, Prosp. Vernadskogo, 76, 119454 Moscow, Russian Federation, platonovani@gmail.com, https://orcid.org/0000-0002-2603-3025

Valeria M. Vargina, Student, Faculty of Management and Politics, MGIMO University, Prosp. Vernadskogo, 76, 119454 Moscow, Russian Federation, valeria.vargina@gmail.com, https://orcid.org/0000-0003-3967-6326

\section{Информация об авторах}

Наталья Игоревна Платонова, кандидат юридических наук, доцент кафедры правовых основ управления, Московский государственный институт международных отношений (университет) при Министерстве иностранных дел Российской Федерации, просп. Вернадского, 76, 119454 г. Москва, Российская Федерация, platonovani@gmail.com, https://orcid.org/0000-0002-2603-3025

Валерия Михайловна Варгина, студент факультета управления и политики, Московский государственный институт международных отношений (университет) при Министерстве иностранных дел Российской Федерации, просп. Вернадского, 76, 119454 г. Москва, Российская Федерация, valeria.vargina@gmail.com, https://orcid.org/0000-0003-3967-6326 